\title{
Keterampilan Penting Sebelum Anak Siap Menulis
}

\author{
Windi Dwi Andika ${ }^{\circledR}{ }^{凶}$, Febriyanti Utami ${ }^{1}$, Sri Sumarni ${ }^{1}$, Bunda Harini ${ }^{2}$ \\ Pendidikan Guru Pendidikan Anak Usia Dini, Universitas Sriwijaya, Indonesia(1) \\ Pendidikan Guru Sekolah Dasar, Universitas Sriwijaya, Indonesia(2) \\ DOI: $\underline{10.31004 / \text { obsesi.v6i4.1973 }}$
}

\begin{abstract}
Abstrak
Adanya kesenjangan antara orang tua yang menginginkan anaknya segera terampil menulis dan fakta bahwa anak memerlukan kesiapan fisik yang matang dalam menulis. Kesenjangan tersebut menimbulkan pertanyaan apa saja keterampilan yang penting distimulasi sebelum anak siap menulis. Tujuan penelitian ini mengkaji literatur hasil penelitian tentang keterampilan sebelum anak siap menulis. Metode penelitian adalah studi literatur dari sumber primer. Hasil kajian literatur menyatakan terdapat: kekuatan otot inti, menyilangkan garis tengah, menggenggam pensil dengan benar, koordinasi mata-tangan, integrasi bilateral, kekuatan tubuh bagian atas, manipulasi objek, persepsi visual, dominasi tangan visual. Kebaharuan penelitian ini mengkaji informasi tentang sembilan keterampilan yang harus distimulasi sebelum anak siap menulis dari 45 hasil penelitian terbaru. Dampaknya guru dapat memfokuskan pengembangan keterampilan tersebut secara optimal sehingga anak tidak mudah letih saat menulis dan anak dapat menggunakan keterampilan pada aktivitas lebih kompleks. Simpulan pentingnya stimulasi keterampilan tersebut sebagai indikator kesiapan menulis anak.
\end{abstract}

Kata Kunci: keterampilan pra-menulis; bahasa; anak usia dini.

\begin{abstract}
This gap raises the question of what skills are essential to be stimulated before the child is ready to write. This study aimed to examine the literature on essential skills before children are ready to write. The research method is a literature study from primary sources. Finding stated that there was: core muscle strength, crossing midline, grasping the pencil correctly, eye-hand coordination, bilateral integration, upper body strength, object manipulation, visual perception, visual hand dominance. The novelty of this study examines information about nine skills that must be stimulated before children are ready to write from 45 recent research results. As a result, teachers can develop these skills optimally so that children do not get tired quickly when writing and can use more complex fine motor skills. In conclusion, these skills are essential to be stimulated before children are ready to write.
\end{abstract}

Keywords: pre-writing skills; language; early childhood.

Copyright (c) 2022 Windi Dwi Andika, et al.

$\triangle$ Corresponding author :

Email Address : windiandika@fkip.unsri.ac.id (Palembang, Indonesia)

Received 18 September 2021, Accepted 13 December 2021, Published 21 January 2022 


\section{PENDAHULUAN}

Menulis adalah aktivitas menuangkan ide, gagasan, dan kreatifitas diri dalam rangkaian kata dan kalimat sehingga membentuk tulisan yang terstruktur. Menulis merupakan aktivitas yang bukan hanya mengandalkan kemampuan kognitif anak, melainkan membutuhkan koordinasi antara mata dan tangan. Kemampuan menulis juga sangat akrab dengan berbagai profesi, diantaranya: jurnalis, dosen, penulis naskah, editor, copy writer, novelis, penerjemah, content writer, blogger, dan lainnya. Kemampuan menulis penting dikuasai seorang professional karena kemampuan ini memudahkan seseorang mengkomunikasikan gagasannya melalui tulisan, serta mencerminkan kecerdasan seseorang.

Paradigma yang berkembangan di masyarakat tentang "pentingnya aktivitas menulis untuk dikuasai seseorang", mendorong para orang tua mengajarkan anaknya menulis sedini mungkin. Bertolak belakang dengan fakta di lapangan bahwa praktik menulis yang terjadi di Lembaga PAUD tidaklah sesuai tahap perkembangan anak. Guru-guru cenderung memaksakan anak dengan aktivitas paper and pencil. Padahal usia TK adalah usia anak mengembangkan keterampilan pra menulis mereka. Ada beberapa keterampilan yang menandai seorang anak usia dini siap atau belum siap untuk dilatih menulis. Untuk itu artikel ini akan mengkaji permasalahan tentang "Keterampilan-keterampilan penting apa yang harus dikembangkan sebelum anak siap untuk menulis", sehingga permasalahan penelitian ini dapat terselesaikan.

Hasil Penelitian sebelumnya yang relevan dengan keterampilan menulis diantaranya (Queroda, 2018) menyatakan bahwa keterampilan pra-menulis perlu dikembangkan pada anak. Senada dengan yang diungkapkan (Serpa-Andrade et al., 2021) bahwa pemerolehan keterampilan pra-menulis juga berkembang pada masa kanak-kanak. Penelitian lain menyebutkan adanya peran perangkat teknologi dalam mengajarkan menulis (Alsamadani, 2017; Yeh et al., 2020). (Skar et al., 2020) memandang bahwa kegiatan menulis anak usia sekolah sebaiknya diberikan stimulasi pada anak. Berdasarkan penelitian (Mohammed \& AlNoori, 2020) menyatakan kemampuan menulis anak akan berkembang dengan brainstorming dimana akan membantu anak mengembangkan ide tulisan. Adanya relevansi antara keterampilan menulis dengan kesadaran fonologis (Yalçıntaş sezgin et al., 2019). Sudut pandang berbeda tentang gender membuktikan bahwa identifikasi keterampilan menulis anak perempuan lebih baik disbanding anak laki-laki (Adams \& Simmons, 2019). Meskipun begitu pada anak dengan kebutuhan khusus sangat membutuhkan pendampingan untuk melakukan aktivitas menulis (Ioannidi \& Samara, 2019). Aktivitas menulis teruntuk anak berkebutuhan khusus dapat distimulasi dengan aktivitas yang penggunaan media yang sesuai (Ahadianingsih et al., 2021).

Hasil penelitian lainnya menyatakan pentingnya menulis di sekolah pada usia 6 tahun manfaatnya tidak dapat digantikan dengan keyboard ataupun perangkat gadget lainnya karena anak membutuhkan keterampilan persepsi visual (Sze \& Southcott, 2020). Selain itu penelitian serupa menguji penggunaan iPad untuk anak belajar menulis, namun tetap saja penggunaan iPad tidak dapat digunakan secara menyeluruh, karena keterampilan menulis anak juga penting dikembangkan karena koordinasi gerak mata dan tangannya tidak dapat digantikan (Dunn \& Sweeney, 2018). Penelitian membuktikan bahwa orang tua yang menstimulasi aktivitas pra menulis anak 4-5 tahun di rumah akan memberikan dampak positif terhadap perkembangan menulis anak (Puranik et al., 2018). Penelitian juga membuktikan bahwa adanya berbagai metode agar anak mudah menulis dengan melafalkan huruf yang ditulis (Baisov, 2021). Pemberian stimulasi pada kurikulum anak usia dini lebih menekankan pemberian pengalaman menulis dengan cara yang menyenangkan agar keterampilan menulis nantinya berkembang optimal (Bingham et al., 2018). Stimulasi yang dapat diberikan sebelum anak menulis seperti mewarnai, menggunting, mengelem, merobek kertas (Naidoo \& Moran, 2020).

Berbeda dengan penelitian sebelumnya, penelitian ini memiliki kebaharuan yang belum pernah dibahas sebelumnya. Kebaharuan dari penelitian ini mencakup: (1) Penelitian 
ini memfokuskan pada pemberian informasi tentang berbagai keterampilan yang dapat distimulasi agar dapat mengidentifikasi kesiapan anak menulis, (2) Berbeda dengan metode penelitian sebelumnya pada topik serupa, penelitian ini menggunakan metode kualitatif studi kajian pustaka, (3) Literatur yang dikaji dalam penelitian ini sebanyak 45 jurnal penelitian pada lima tahun terakhir sejak tahun 2017 hingga 2021 pada topik yang memfokuskan tentang keterampilan sebelum anak siap menulis.

Banyak manfaat baik yang didapat oleh pendidik khususnya orang tua, guru, dan stakeholder tentang keterampilan penting yang harus dikembangkan sebelum mempersiapkan anaknya menulis. Mengingat gencarnya kursus menulis yang diadakan berbagai Lembaga Kursus bagi anak usia dini yang mengabaikan stimulasi menulis sesuai perkembangan anak. Pada kasus ini, hasil penelitian sungguhlah mempermudah pembaca untuk mengidentifikasi dan menstimulasi kesiapan anak dalam menulis. Manfaat tersebut sangatlah relevan dengan tujuan penelitian ini untuk mengkaji berbagai literatur yang relevan dengan topik keterampilan penting anak sebelum mereka siap menulis.

\section{METODOLOGI}

Penelitian yang digunakan adalah desain penelitian kualitatif pada pendekatan literature review. Alasan metode ini dipilih karena berdasarkan tujuan penelitian yaitu mengkaji 45 literatur dengan topik yang relevan. Penelitian ini mengkaji sumber primer dari berbagai hasil penelitian yang berasal dari jurnal yang terpublikasi pada lima tahun terakhir dan tersebar lima benua. Metode pengumpulan sumber data yang digunakan diantaranya pencarian kata kunci pada lima laman pencarian jurnal, seperti:, ScienceDirect, ResearchGate, tandfonline, wiley \& sons, dan google scholar. Peneliti hanya mengutip referensi yang relevan dengan topik "keterampilan penting sebelum anak siap menulis" pada lima tahun terakhir sejak tahun 2017 hingga tahun 2021. Waktu pengumpulan data selama 6 bulan sejak March hingga Agustus. Teknik analisis data penelitian ini adalah analisis Miles \& Huberman: (1) memilih data, (2) menampilkan data, dan (3) memverifikasi data. Alur penelitian dapat tergambar pada bagan 1 .

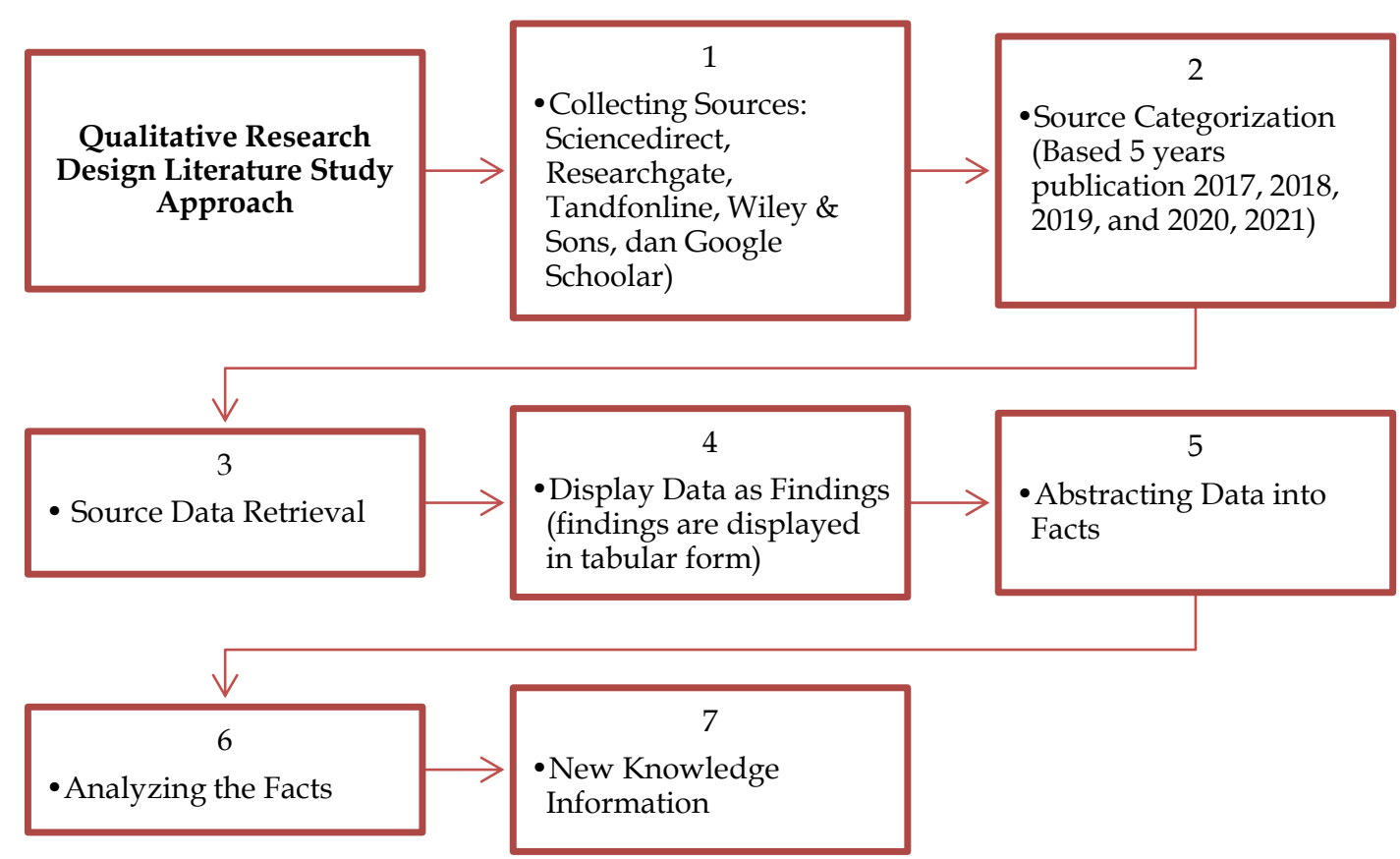

Bagan 1. Research Flow(Snyder, 2019) 


\section{HASIL DAN PEMBAHASAN}

Hasil penelitian yang didasari pendekatan literature study. Konten analisisnya dari sumber primer yakni jurnal penelitian yang dikategorisasi berdasarkan tahun publikasi sejak tahun 2017 hingga 2021. Hal ini tergambar dari temuan pada bagan 2.

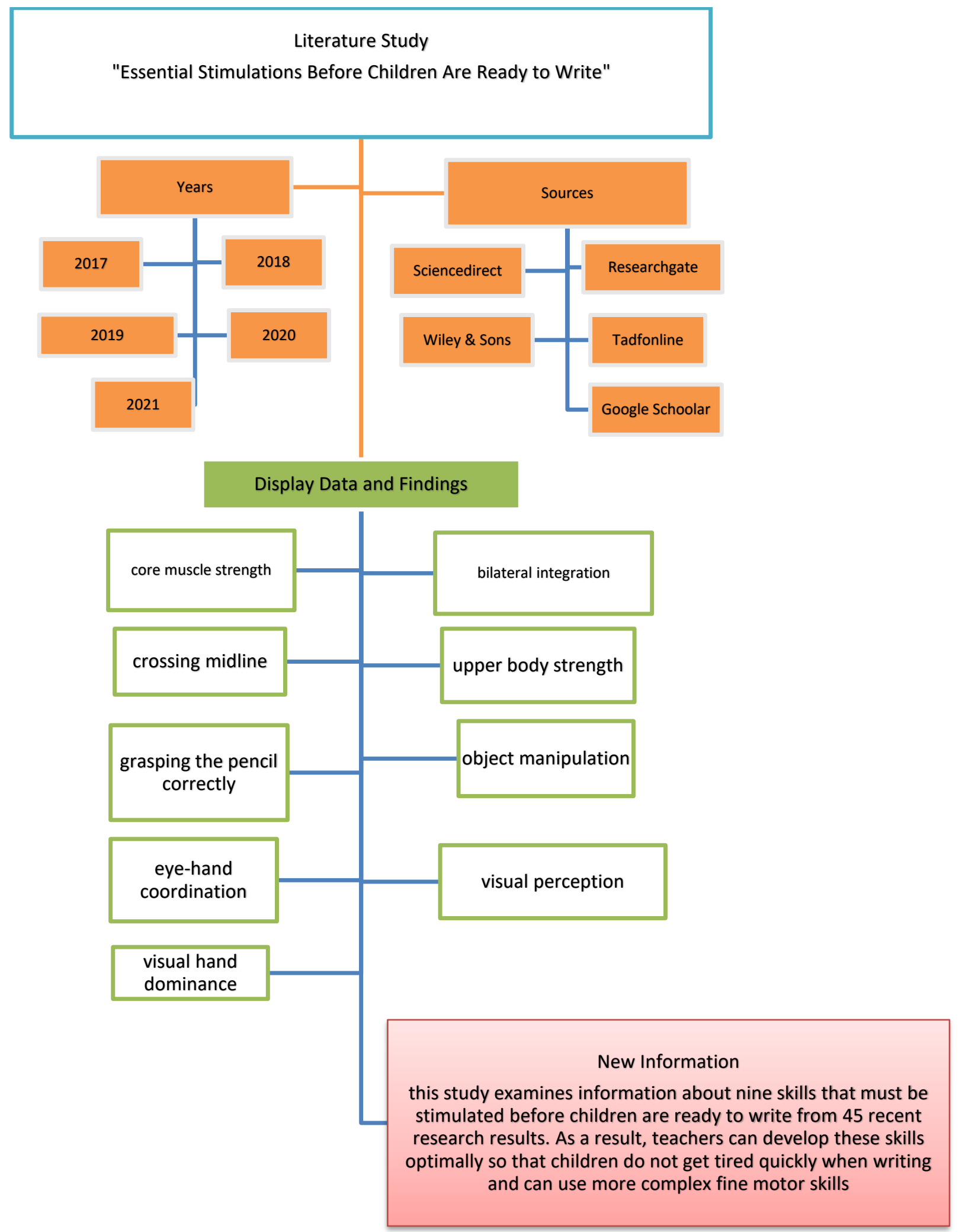

Bagan 2. Research Result 
Diagram tersebut menggambarkan temuan penelitian yang dihasilkan dari analisis 45 literature. Semua literature bersumber dari laman lima pencarian jurnal diantaranya: sciendirect, researchgate, tandfonline, wiley \& sons, dan google schoolar. Pencarian dilakukan dengan mengakses laman-laman tersebut selama lima bulan. Selain itu jurnal yang dikaji adalah jurnal yang terbit pada lima tahun terakhir mulai dari 2017 hingga 2021. Alasan pemilihan lima periode, karena peneliti ingin mengkaji literature terbaru untuk topik yang dibahas. Literature yang dikaji adalah literatur yang relevan dengan topik "stimulasi keterampilan sebelum anak siap menulis". Selengkapnya dapat diilustrasikan dengan bagan 3.

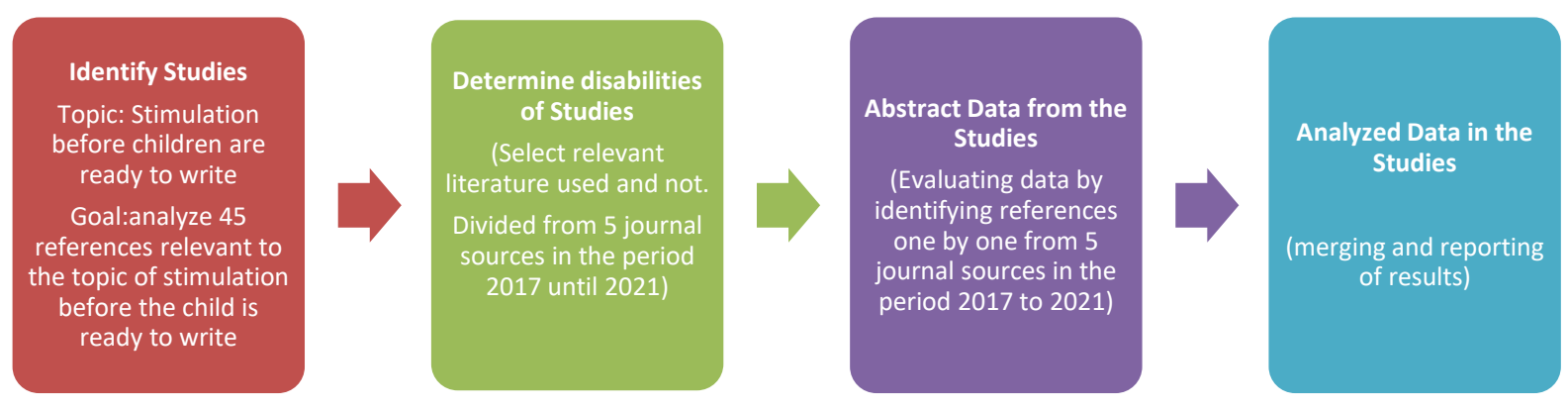

Bagan 3. Implementation of Systematic Review

Implementasi proses analisis literatur dilakukan dengan systematic review. Proses ini terdiri dari empat tahap: (1) Identify Studies: tahap ini merupakan tahap pertama saat peneliti menentukan topik dan tujuan penelitian. Topik yang dikaji dalam penelitian ini merupakan "stimulasi keterampilan anak sebelum mereka siap menulis", sedangkan tujuan penelitiannya mengkaji 45 literatur yang relevan dengan topik penelitian. (2) Determine disabilities of Studies: tahap ini merupakan tahap memilah dan memilih literatur mana yang relevan dengan topik dan yang tidak, sehingga tahap ini peneliti akan memutuskan mana literatur yang akan digunakan dan tidak digunakan. Literature yang dipilih berasal dari 5 sumber jurnal pada rentang waktu 2017 hingga 2021. Proses ini dilakukan dengan mengakses keyword yang relevan dengan topik pada laman sumber jurnal mulai dari sciencedirect, researchgate, tandfonline, wiley \& sons, dan google scholar. Kemudian peneliti setting periode jurnal yang terpublikasi 5 tahun terakhir, yakni sejak tahun 2017 hingga 2021.

(3) Abstract data from the studies: tahap ini yaitu tahap peneliti mengidentifikasi 45 artikel jurnal satu persatu dari hasil pencarian lima sumber jurnal sejak lima tahun terakhir. Tahap ini dilakukan peneliti dengan membuat table agar mempermudah mengabstraksi data setiap artikel jurnal. Kriteria yang identifikasi pada setiap artikel jurnal meliputi: sumber jurnal, penerbit, negara, tahun, dan temuan penelitian. Setelah 45 jurnal diidentifikasi berdasarkan kriteria yang telah ditentukan, barulah peneliti mengkaji satu persatu relevansi temuan penelitian dengan topik. Hasil abstraksi data tentang jumlah sumber jurnal pada lima tahun terakhir yang dikaji dapat digambarkan pada grafik 4.

Artikel yang diakses dari laman pencarian jurnal "sciencedirect" sejumlah 10 buah diantaranya: ada 5 artikel pada tahun 2018, 3 artikel pada tahun 2019, dan 2 artikel pada tahun 2020. Selanjutnya terdapat tujuh artikel yang diakses dari laman "researchgate" diantaranya: 1 artikel tahun 2017, 4 artikel pada tahun 2018, dan 2 artikel pada tahun 2019. Untuk laman "tandfonline" diakses sebanyak 7 artikel diantaranya: terdapat 2 artikel ada tahun 2018, 2 artikel pada tahun 2020, dan 3 artikel pada tahun 2021. Artikel yang diakses dari laman pencarian jurnal "wiley \& sons" terdapat 2 artikel yang masing-masing artikel terbit pada tahun 2018 dan 2020. Sedangkan untuk akses laman "google schoolar" terdapat 20 artikel yang tersebar sebanyak 2 artikel pada tahun 2017, 9 artikel pada tahun 2021, 3 artikel pada tahun 2019, 3 artikel tahun 2020, dan 2 artikel pada tahun 2021. Dari grafik 4 dapat terlihat jelas bahwa paling dominan artikel yang diakses bersumber dari laman google schoolar dan 
sciencedirect, kemudian researchgate dan tandfonline, sedangkan yang paling sedikit artikel yang bersumber dari laman wiley \&sons.

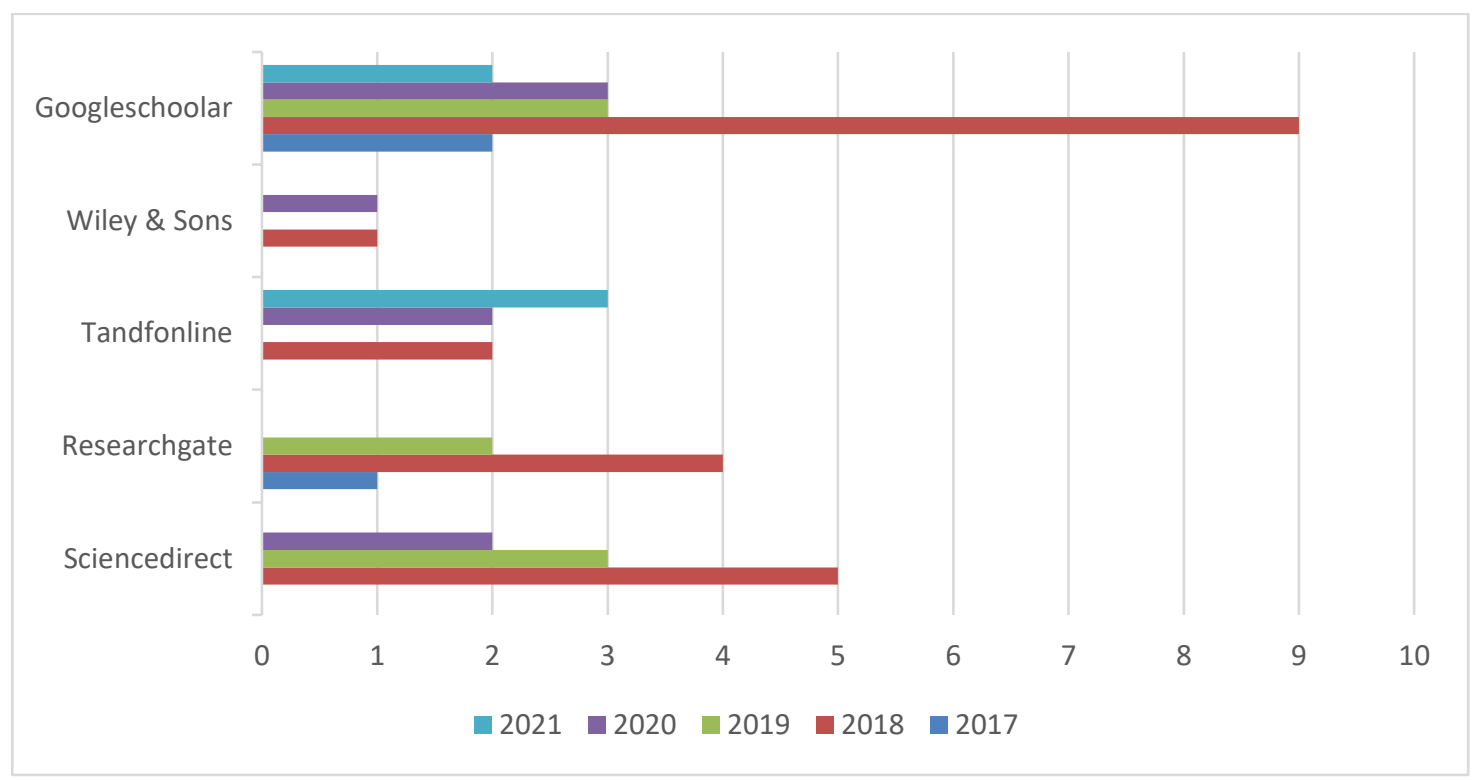

Grafik 4. Journal Sources from 2017-2021

Selain itu hasil abstraksi data pada 45 jurnal yang direvieu dari berbagai negara dikategorisasi dalam lima benua diantaranya: Asia, Europe, Australia, America, dan Africa. Diagram lingkaran ini menunjukan persentase jurnal yang dikaji pada setiap benua. $20 \%$ jurnal yang dikaji sejak tahun 2017 hingga 2021 berasal dari benua Asia diantaranya negara: Indonesia, Thailand, Hong Kong. 33\% berasal dari benua Europe diantaranya negara: UK, Germany, Austria, Spain, Berlin, Italia, Poland, Frence, Sweden, England, Slovenia, Switzerland. 7\% berasal dari benua Australia diantaranya negara: Australia. 38\% berasal dari benua America diantaranya negara: Canada, Portugal, Michigan, USA, Minesota, Chicago, Brazil. 2\% berasal dari benua Africa diantaranya negara South Africa. Data persentase sumber literatur setiap benua pada lima terakhir tergambar pada gambar 1 .

45 Journals Reviewed from 5 Continents in 2017 to 2021

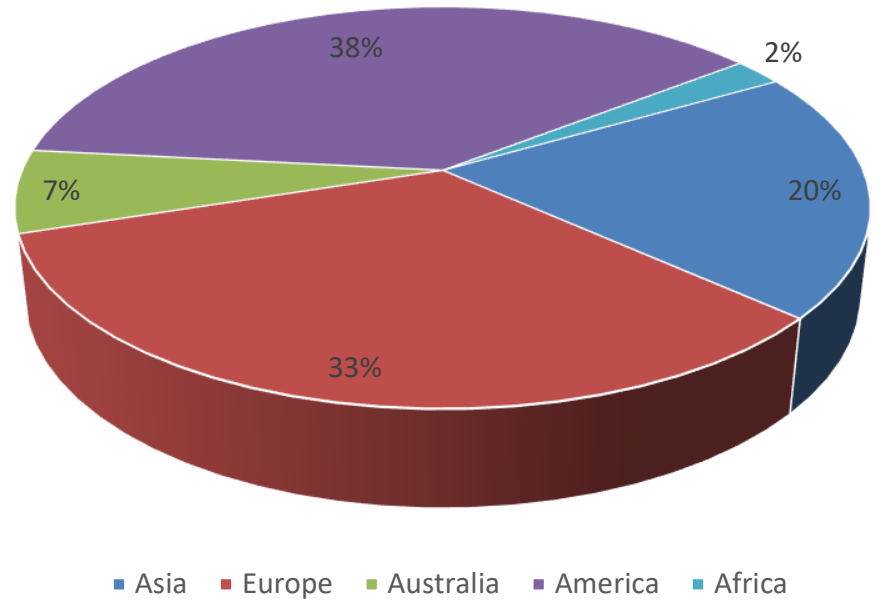

Gambar 1. Percentages of Literature Sources from 5 Continents 
(4) Analysed data in the studies: tahap keempat ini merupakan tahapan analisis hasil abstraksi data yang telah dibuat pada tahap sebelumnya. Tahap ini menganalisis temuan penelitian pada 45 artikel yang dikaji dari 5 sumber laman pencarian artikel jurnal pada 5 tahun terakhir, kemudian menganalisis relevansinya dengan topik yaitu keterampilan penting sebelum anak siap menulis. Analisis dilakukan dengan cara mengidentifikasi temuan setiap artikel dengan mengkaji lebih detail bab hasil, pembahasan, dan kesimpulan. Kemudian menyimpulkan temuan secara keseluruhan tentang skill penting apa saja yang perlu distimulasi sebelum anak siap menulis. Adapun hasil analisis data penelitian ini dapat digambarkan pada tabel 1.

Tabel 1. Table of Analysis

\begin{tabular}{|c|c|c|c|c|c|c|}
\hline No. & Source & 2017 & Ove & $\begin{array}{l}2019 \\
\text { rall Findings }\end{array}$ & 2020 & 2021 \\
\hline 1 & Sciencedirect & - & $\begin{array}{l}\text { core muscle strength, } \\
\text { crossing midline, } \\
\text { eye-hand } \\
\text { coordination, } \\
\text { bilateral integration, } \\
\text { upper body strength, } \\
\text { visual perception }\end{array}$ & $\begin{array}{l}\text { core muscle } \\
\text { strength, } \\
\text { object } \\
\text { manipulation, } \\
\text { visual } \\
\text { perception }\end{array}$ & $\begin{array}{l}\text { visual } \\
\text { perception, } \\
\text { visual hand } \\
\text { dominance }\end{array}$ & - \\
\hline 2 & Researchgate & $\begin{array}{l}\text { visual } \\
\text { perception }\end{array}$ & $\begin{array}{l}\text { core muscle strength, } \\
\text { crossing midline }\end{array}$ & $\begin{array}{l}\text { object } \\
\text { manipulation, }\end{array}$ & - & - \\
\hline 3 & Tandfonline & - & $\begin{array}{l}\text { grasping the pencil } \\
\text { correctly, eye-hand } \\
\text { coordination }\end{array}$ & $\begin{array}{l}\text { crossing } \\
\text { midline }\end{array}$ & $\begin{array}{l}\text { visual hand } \\
\text { dominance }\end{array}$ & $\begin{array}{l}\text { grasping the } \\
\text { pencil } \\
\text { correctly, } \\
\text { eye-hand } \\
\text { coordination }\end{array}$ \\
\hline 4 & Wiley\& Sons & - & crossing midline & $\begin{array}{l}\text { object } \\
\text { manipulation }\end{array}$ & - & \\
\hline 5 & $\begin{array}{l}\text { Google } \\
\text { Schoolar }\end{array}$ & $\begin{array}{l}\text { crossing } \\
\text { midline, } \\
\text { object } \\
\text { manipulation }\end{array}$ & $\begin{array}{l}\text { crossing midline, } \\
\text { grasping the pencil } \\
\text { correctly, grasping } \\
\text { the pencil correctly, } \\
\text { eye-hand } \\
\text { coordination, } \\
\text { bilateral integration, } \\
\text { upper body strength }\end{array}$ & $\begin{array}{l}\text { upper body } \\
\text { strength, } \\
\text { visual hand } \\
\text { dominance }\end{array}$ & $\begin{array}{l}\text { grasping the } \\
\text { pencil } \\
\text { correctly, } \\
\text { object } \\
\text { manipulation, } \\
\text { visual hand } \\
\text { dominance }\end{array}$ & $\begin{array}{l}\text { eye-hand } \\
\text { coordination, } \\
\text { bilateral } \\
\text { integration, } \\
\text { visual hand } \\
\text { dominance }\end{array}$ \\
\hline
\end{tabular}

Berdasarkan analisis data, maka temuan penelitian terdapat sembilan keterampilan penting untuk distimulasi sebelum anak siap menulis diantaranya: core muscle strength, crossing midline, grasping the pencil correctly, eye-hand coordination, bilateral integration, upper body strength, object manipulation, visual perception, visual hand dominance. Sembilan keterampilan tersebut menunjukan indikasi kesiapan menulis anak hingga penguasaan menulis yang baik.

Core muscle strength, melatih kekuatan otot inti maksudnya adalah kekuatan otot jemari dan tangan saat digunakan untuk menulis. Kekuatan ini peting untuk mengontrol gerakan tangan dan jemari saat mengendalikan alat tulis yang digunakan. Kekuatan otot inti jika distimulasi dengan baik, maka akan berdampak positif terhadap penguasaan keterampilan motoric yang baik pula (Yu et al., 2018). Kekuatan otot perlu dilatih agar mengurangi cedera pada masa mendatang, begitu juga dengan kekuatan otot inti (Kernc et al., 2018). Semakin otot tangan dan jemari anak terlatih, maka mengurangi dampak cedera otot saat mengkoordinasikan berbagai alat tulis dan peralatan lainnya. Cedera otot yang biasa terjadi ketika anak menulis yaitu otot yang membalut ruas jari akan terasa nyeri dan membiru. Senada dengan pernyataan bahwa anak dengan gangguan koordinasi ternyata berpengaruh terhadap penguasaan kompetensi motoriknya (Cairney et al., 2019). Untuk penting sekali 
mengembangkan kekuatan otot inti sebelum anak siap menulis agar menghindarkan cidera dan tidak optimalnya penguasaan kompetensi anak dalam menulis nantinya.

Crossing midline, merupakan keterampilan untuk menggerakkan tangan melintasi garis tengah tubuh untuk mengambil atau mengkoordinasikan benda di sisi tubuh lainnya. Setiap manusia memiliki garis tengah yang membagi kedua sisi tubuhnya, garis inilah dinamakan garis tengah tubuh. Keterampilan melewati garis tengah tubuh ternyata sangatlah penting untuk mengembangkan preferensi tagan, kemampuan anak dalam membentuk sebuah huruf, dan sangatlah diperlukan kemampuan menulis anak (Richmond, L., \& Marks, 2019). Penelitian menemukan bahwa seseorang akan melibatkan proses berpikirnya untuk menghindarkan dirinya dari tindakan yang merugikan begitu pun ketika anak akan melintasi garis tengah untuk melakukan tugas, maka mereka akan mempertimbangkannya secara logis untuk memutuskan tangan mana yang akan digunakan dan seberapa besar kesulitan dalam mengerjakan tugas tersebut (Liang et al., 2018). Penelitian tersebut didukung dengan pernyataan bahwa adanya pengaruh kendala spasial terhadap penggunaan tangan anak saat menggerakkan tangan melintasi garis tengah tubuh (Catela, 2018). Studi lain membuktikan bahwa gerakan melintasi garis tengah berkaitan dengan waktu reaksi tangan dominan pada seseorang (Liang et al., 2019). Artinya keterampilan ini membutuhkan stimulasi agar anak dapat menguasai keterampilan melintasi garis tengah tubuh dengan memberikan reaksi tangan dominan yang cepat. Keterampilan melintasi garis tengah tubuh dapat dilakukan dengan memanipulasi objek secara unimanual dan bimanual (Scharoun Benson et al., 2018). Temuan penelitian menyatakan adanya hubungan perkembangan antara keterampilan melintasi garis tengah dan koordinasi bimanual serta visual-manual saat anak-anak melakukan bermain papan pasak (Serrien \& O'Regan, 2021). Artinya keterampilan melintasi garis tengah tubuh dapat distimulasi dengan aktivitas bermain papan pasak. Meninjau berbagai hasil penelitian tentang keterampilan gerak melintasi garis tengah tentunya sangat penting untuk dikembangkan pada anak sebelum mereka siap menulis.

Grasping the pencil correctly, merupakan keterampilan dalam menggenggam pensil dengan benar. Sebenarnya keterampilan ini sudah berkembang pada usia bayi. Genggaman adalah keterampilan hasil dari koordinasi otak, otot tangan dan jemari, serta mata. Semakin baik control genggaman, maka nantinya akan berdampak pada kesiapan anak dalam menulis. Hasil penelitian menyebutkan bahwa seiring perkembangan teknologi, keterampilan motorik halus anak khususnya menggenggam mengalami penurunan. Hal ini dikarenakan pengguna gadget sehingga anak jarang terstimulasi genggamannya. Oleh karena itu, penelitian ini bertujuan untuk memfasilitasi anak 4-6 tahun untuk belajar menggenggam, namun tetap menggunakan media gadget. Anak dapat distimulasi menggenggam pensil yang dirancang khusus untuk sebuah tablet (Whittaker et al., 2019). Penelitian lain terbukti bahwa keterampilan menggenggam pensil dengan benar berhubungan dengan kematangan otot tangan dan jemari (Donica et al., 2018). Selain itu genggaman pensil saat menulis juga berkaitan erat dengan keterbacaan tulisan. Semakin terbaca dan tulisan yang baik, maka akan semakin menurun kelancaran anak dalam menulis. Artinya genggaman juga berhubungan erat dengan kelancaran, keterbacaan, serta penempatan tulisan yang sesuai (Galloway, 2018). Gengaman pensil anak usia 5 tahun sangat menentukan integrasi motoric visual, kemahiran motorik keseluruhan, dan kemahiran motorik halus anak (Sheedy et al., 2021). Penelitian menyebutkan adanya pengaruh yang signifikan antara kekuatan menggenggam pensil dengan keterampilan menulis anak. Oleh karena itu, maka keterampilan menggenggam pensil dengan benar sangatlah penting distimulasi sebelum anak siap menulis pada usia sekolah (Kadaskar \& Borkar, 2020).

Eye-hand coordination, merupakan keterampilan saat anak menerima informasi dari indera penglihatan kemudian mengoordinasi dengan tangan untuk melakukan tugas seperti menulis. Keterampilan koordinasi mata dan tangan anak ternyata menurun pada era digitalisasi karena anak cenderung menggunakan perangkat digital (Sheedy et al., 2021). Kematangan otot-otot sangat mempengaruhi koordinasi mata tangan anak (Donica et al., 
2018). Koordinasi mata dan tangan sangat dibutuhkan agar anak dapat mencengkeram alat tulis (Liang et al., 2018). Penelitian lain menegaskan bahwa penggunaan tangan sangat menentukan koordinasi mata tangan saat anak memanipulasi benda (Scharoun Benson et al., 2018). Persepsi visual khususnya koordinasi mata dan tangan sangat berpengaruh signifikan dengan keterbacaan tulisan (Lee, 2021). Huruf yang sering anak jumpai membuat anak mudah untuk menuliskan huruf tersebut. Artinya pengenalan huruf melalui visual akan memberikan efek otomatisasi ketika anak akan menulis. Hal ini dikarenakan otak telah menerima informasi dari visual kemudian diteruskan dengan control tangan dan jemarinya (Fears \& Lockman, 2018). Untuk itu koordinasi mata dan tangan menjadi salah satu keterampilan penting yang disarankan untuk distimulasi sebelum anak siap menulis.

Bilateral integration, adalah kemampuan yang digunakan anak untuk melakukan tugas sama atau berbeda oleh kedua tangannya secara bersamaan, sehingga keterampilan ini penting dipromosikan karena berkaitan erat dengan keterampilan melintasi garis tengah tubuh anak yang tentunya kedua keterampilan ini dibutuhkan untuk keterampilan menulis anak prasekolah (Ortiz \& Ortiz, 2020). Keterampilan gerak dasar yang melibatkan keterampilan integrasi bilateral berpengaruh signifikan terhadap prestasi akademik akan usia 5-6 tahun (de Waal, 2019). Integrasi bilateral diperlukan untuk anak bisa menyalin hurufhuruf. Jika saat melakukan gerak integrasi bilateral anak mengalami kesulitan. Artinya hal ini akan mengganggu keterampilan menulis dengan tangan di masa mendatang (Fung \& Tse, 2018). Stimulasi integrasi bilateral bukan hanya dapat dilakukan dengan tugas-tugas yang berkaitan dengan tangan, melainkan juga tugas-tugas yang menggunakan kaki. Orang dengan integrasi bilateralnya baik tentunya akan mudah mengontrol gerakan kakinya saat berjalan dan menuruni tangga. Integrasi bilateral melibatkan gerakan tangan dan kaki dapat dijadikan stimulasi agar anak terlatih melakukan tugas berbeda secara bersamaan. Hal ini tentunya akan berdampak pada kesiapan keterampilan menulis anak (Hu et al., 2018).

Upper body strength, kekuatan tubuh bagian atas berkaitan erat dengan kekuatan kepala, leher, bahu, punggung, pinggang, dan lengan anak. Sebenarnya bagian tubuh atas sebenarnya distimulasi sejak anak usia bayi, dengan kegiatan merangkak salah satunya (Valentini \& Lamanna, 2018). Stabilitas kekuatan bahu yang baik akan mempermudah anak mengontrol gerakan tangan dan jari (Memon et al., 2021). Anak akan membutuhkan kemampuan dalam menstabilkan tubuh dan leher untuk berkoordinasi dengan lengan dan tangan untuk menulis. Jika stabilitas terganggu, tentunya akan mempersulit anak menulis ditambah dengan adanya keluhan tentang rasa lelah dan nyeri pada lengan saat menulis (Erlianda et al., 2019). Meningkatkan keterampilan motorik halus anak dapat dilakukan dengan memberikan stimulasi (Agustina et al., 2018). Untuk itu menstimulasi kekuatan tubuh bagian atas merupakan hal penting dilakukan sebelum anak siap menulis.

Object manipulation, kegiatan keseharian akan membutuhkan manipulasi objek, khususnya dalam hal ini aktivitas manipulasi alat tulis yang digunakan untu menulis (Maulana, 2017).. Jika keterampilan manipulasi objek sulit anak kuasai, hal ini berdampak pada rasa frustrasi pada anak, sehingga anak enggan mencoba dan melatih keterampilan ini lagi. Kegiatan memanipulasi benda dapat dilatih dengan berbagai benda yang variative sebelum anak menggunakan pensil. Seperti kegiatan memotong, menyekop, menyendok, mengaduk dan sebagainya (Gajewski et al., 2019). Semakin baik keterampilan manipulasi seseorang, membuat mereka mampu merancang robot yang dapat mempermudah pekerjaan manusia (Bütepage et al., 2019; Erlianda et al., 2019; Kim et al., 2021). Memandang hal ini sekolah memiliki peran besar dalam menstimulasi keterampilan manipulasi anak (Eddy, LH, Wood, ML, Shire, 2019).

Visual perception, berkaitan dengan kemampuan otak untuk memproses informasi tentang letak benda, informasi tersebut akan diteruskan menuju otot dan sendi-sendi untuk menmbuat diri anak sadar akan posisi benda benda yang dilihat, seberapa jauh tangan akan bergerak untuk meraih dan memanipulasi benda yang dilihat. Visual persepsi ini juga membutuhkan "body awareness" untuk bisa berkembang optimal. Keterampilan persepsi 
gerak berhubungan dengan kecemasan dan situasi (Runswick et al., 2018). Pengalaman motorik baru tentunya memfasilitasi eksplorasi anak terhadap lingkungannya mulai dari posisi orang di sekitarnya, benda serta tempat baru (Franchak, 2020). Persepsi visual dipengaruhi juga oleh kemampuan kognitif anak karena semakin tinggi tingkat kognitif anak, maka semakin mudah bagi anak melakukan gerakan dan menghindarkan mereka dari gerakan yang keliru (Jiang \& Rosengren, 2018). Penelitian lain membuktikan perbedaan tingkat persepsi visual pada anak yang tidak menggunakan tablet dibandingkan yang menggunakan tablet. Secara signifikan kelompok anak yang tidak menggunakan tablet lebih baik dalam melakukan diskriminasi visual, memori visual, hubungan spasial, mengidentifikasi struktur bentuk, gambar, presisi motoric halus, integrasi motoric halus, dan ketangkasan gerak, dibandingkan anak yang menggunakan tablet (Lin, 2019). Oleh sebab itu penggunaan tablet sangat tidak disarankan karena menghambat penguasaan persepsi visual anak, yang merupakan salah satu keterampilan penting sebelum anak siap menulis. Namun penelitian lain menekankan adanya peran penting dari perkembangan teknologi terhadap keterampilan anak. Pelatihan berbasis iPad terbukti efektif bagi anak usia 5-10 tahun yang mengalami disgrafia (John \& Renumol, 2018). Jika dipandang dari kedua penelitian tersebut tentulah penelitian tersebut merupakan kasus yang berbeda. Bagi anak dengan gangguan menulis (disgrafia) penggunaan teknologi gadget mungkin efektif, namun tidak dengan anak tanpa gangguan menulis. Penggunaan tablet justru membuat menurunnya kemampuan persepsi visual anak, yang berdampak pada kesiapan anak dalam menulis.

Visual hand dominance, keterampilan menggunakan satu tangan secara konsisten untuk mengerjakan suatu tugas tertentu. Keterampilan ini akan dapat berkembang baik, jika keterampilan dalam memaipulasi objek seiring berkembang optimal. Penelitian membuktikan penggunaan tangan dominan berkaitan pada dominasi belahan otak anak, dan kebiasaan membaca anak (Rinaldi et al., 2020). Pemilihan tangan dominan berkaitan dengan kemampuan anak menggunakan jempol, jari telunjuk, dan jari tengah saja untuk memanipulasi benda. Anak akan membiarkan jari manis dan jari kelingking terlipat ke telapak tangannya karena berguna untuk menstabilkan gerakan 3 jari lainnya. Penelitian lain membuktikan tidak terdapat hubungan antara kegiatan olahraga dengan atau tidak menggunakan tangan dominan terhadap keterampilan motoric halus anak 4 tahun (Rahayu et al., 2021). Artinya menggunakan tangan manapun untuk melakukan aktivitas olahraga tidaklah berpengaruh terhadap kecakapan anak dalam menulis. Hal ini tentulah dua hal yang berbeda, karena aktivitas olahraga cenderung menstimulasi keterampilan motoric kasar, sedangkan penggunaan tangan dominan lebih berperan terhadap penguasaan motoric halus. Penelitian juga membuktikan adanya kelainan musculoskeletal saat anak lebih dominan menggunakan tangan kiri saat menulis. Hal ini dikarenakan anak kidal harus membongkokkan leher sebesar 40 derajat untuk bisa menulis. Postur canggung yang ditampilkan anak kidal menulis (Nurwulan \& Kristiani, 2020). Penelitian lain menyebutkan bahwa kidal memiliki intelegensia visual yang lebih baik dibandingkan tangan kanan (Natalia \& Dwiana, 2019). Setiap penggunaan tangan dominan baik kanan atau kiri tentunya masingmasing memiliki keunggulan dan kelemahannya. Pemilihan dalam penggunaan tangan dominan akan lebih baik fungsinya dibandingkan tangan tidak dominan (Jones et al., 2021). Ditinjau dari berbagai sebelumnya, maka keterampilan visual tangan dominan sangat penting dikembangkan sebelum anak siap menulis.

Kebaharuan dalam penelitian ini terletak pada ditemukannya berbagai keterampilan yang seharusnya distimulasi guna mempersiapkan anak dalam aktivitas menulis dari 45 kajian literatur. Kesembilan keterampilan ini merupakan hasil analisis kajian pustaka primer pada lima tahun terbaru. Berbeda dengan hasil penelitian Sumarni et al. (2022) yang mengkaji literatur dari 3 sumber yaitu primer, sekunder, dan tersier. Tidak seperti penelitian sebelumnya penelitian ini memiliki keterbatasan yaitu penelitian ini hanya fokus mengkaji sumber primer pada lima tahun terakhir saja. Hal ini dapat menjadi rekomendasi bagi peneliti 
selanjutnya untuk membahas topik ini lebih lanjut dari ketiga sumber dan lebih banyak literatur yang dikaji.

\section{SIMPULAN}

Sembilan keterampilan penting untuk distimulasi sebelum anak siap menulis diantaranya: kekuatan otot inti, menyilangkan garis tengah, menggenggam pensil dengan benar, koordinasi mata-tangan, integrasi bilateral, kekuatan tubuh bagian atas, manipulasi objek, persepsi visual, dominasi tangan visual berdasarkan 45 kajian literatur lima tahun terbaru. Penelitian ini memberikan manfaat positif untuk para orang tua, guru, dan stakeholder mengenai sembilan keterampilan yang harus dikembangkan sejak anak bayi hingga anak siap untuk menulis. Informasi ini dapat menjawab permasalahan global tentang maraknya kursus menulis bagi anak TK bahwa mereka tidak perlu memaksakan anak untuk menulis apalagi memfokuskan pada aktivitas paper and pencil. Selain itu manfaat penelitian relevan tujuan penelitian untuk mengkaji literatur terbaru tentang keterampilan apa saja yang distimulasi sebagai bentuk indikator kesiapan menulis anak.

\section{UCAPAN TERIMA KASIH}

Penelitian/publikasi artikel ini dibiayai oleh: Anggaran DIPA Badan Layanan Umum Universitas Sriwijaya Tahun Anggaran 2021. Nomor SP DIPA-023.17.2.677515/2021, tanggal 23 November 2020, Sesuai dengan SK Rektor 0007/UN9/SK.LP2M.PT/ 2021 tanggal 27 April 2021.

\section{DAFTAR PUSTAKA}

Adams, A. M., \& Simmons, F. R. (2019). Exploring individual and gender differences in early writing performance. Reading and Writing, 32(2), 235-263. https:// doi.org/10.1007/s11145-018-9859-0

Agustina, S., Nasirun, M., \& D, D. (2018). Meningkatkan Keterampilan Motorik Halus Anak Melalui Bermain dengan Barang Bekas. Jurnal Ilmiah Potensia, 3(1), 24-33. https://doi.org/10.23887/jippg.v1i3.16454

Ahadianingsih, M. N., Luar, S., \& Ibnu, B. (2021). The Use of Straw String Media to Improve PreWriting Skills for Children Intellectual Disability. Jurnal Asesmen Dan Intervensi Anak Berkebutuhan Khusus, 22(2), 113-122.

Alsamadani, H. A. (2017). The Effectiveness of Using Online Blogging for Students' Individual and Group Writing. International Education Studies, 11(1), 44. https://doi.org/10.5539/ies.v11n1p44

Baisov, A. S. (2021). The Effectiveness of The Method Talk for Writing in Developing Writing Skilss of EFL Students. Academic Research in Educational Sciences, 3(2), 727-730. https://cyberleninka.ru/article/n/the-effectiveness-of-the-method-talk-for-writing-indeveloping-writing-skills-of-efl-students

Bingham, G. E., Quinn, M. F., McRoy, K., Zhang, X., \& Gerde, H. K. (2018). Integrating Writing into the Early Childhood Curriculum: A Frame for Intentional and Meaningful Writing Experiences. Early Childhood Education Journal, 46(6), 601-611. https://doi.org/10.1007/s10643-018-0894-x

Bütepage, J., Cruciani, S., Kokic, M., Welle, M., \& Kragic, D. (2019). From Visual Understanding to Complex Object Manipulation. Annual Review of Control, Robotics, and Autonomous Systems, 2(1), 161-179. https://doi.org/10.1146/annurev-control-053018-023735

Cairney, J., Dudley, D., Kwan, M., Bulten, R., \& Kriellaars, D. (2019). Physical Literacy, Physical Activity and Health: Toward an Evidence-Informed Conceptual Model. In Sports Medicine (Vol. 49, Issue 3, pp. 371-383). Springer International Publishing. https:// doi.org/10.1007/s40279-019-01063-3

Catela, D. R. (2018). Dynamical analysis of the interaction between object location and hand use in a midline crossing task in children with trisomy 21. Functional Neurology, Rehabilitation, and Ergonomics, 7(3). 
de Waal, E. (2019). Fundamental Movement Skills and Academic Performance of 5- to 6-Year-Old Preschoolers. Early Childhood Education Journal, 0(0), 0. https://doi.org/10.1007/s10643019-00936-6

Donica, D. K., Massengill, M., \& Gooden, M. J. (2018). A quantitative study on the relationship between grasp and handwriting legibility: does grasp really matter? Journal of Occupational Therapy, Schools, and Early Intervention, 11(4), 411-425. https://doi.org/10.1080/19411243.2018.1512068

Dunn, J., \& Sweeney, T. (2018). Writing and iPads in the early years: Perspectives from within the classroom. British Journal of Educational Technology, 49(5), 859-869. https://doi.org/10.1111/bjet.12621

Eddy, LH, Wood, ML, Shire, K. et al. (2019). A systematic review of randomised and casecontrolled trials investigating the effectiveness of school-based motor- skill interventions in 3-12 year-old children. Child: Care, Health \&Development, 45(6), 773-790. https:// doi.org/10.1111/cch.12712

Erlianda, T., Fauzi, A., \& Amri, K. (2019). Meningkatkan Kemampuan Motorik Halus Anak melalui Kegiatan Menulis di Atas Pasir. Aț̣ālunā: Journal of Islamic Early Childhood Education, 2(2), 74-85. https:// doi.org/10.32505/atfaluna.v2i2.1336

Fears, N. E., \& Lockman, J. J. (2018). How beginning handwriting is influenced by letter knowledge: Visual-motor coordination during children's form copying. Journal of Experimental Child Psychology, 171, 55-70. https:// doi.org/10.1016/i.jecp.2018.01.017

Franchak, J. M. (2020). The ecology of infants' perceptual-motor exploration. In Current Opinion in Psychology (Vol. 32, pp. 110-114). https:// doi.org/10.1016/j.copsyc.2019.06.035

Fung, L., \& Tse, L. (2018). Handwriting Performance Among Kindergarten Children in Hong Kong. Gajewski, P., Ferreira, P., Bartels, G., Wang, C., Guerin, F., Indurkhya, B., Beetz, M., \& Śniezyński, B. (2019). Adapting everyday manipulation skills to varied scenarios. Proceedings - IEEE International Conference on Robotics and Automation, 2019-May, 1345-1351. https://doi.org/10.1109/ICRA.2019.8793590

Galloway, K. (2018). Effects of Pencil Grasp Exercises on Handwriting in Sixth Grade Resource Students Effects of Pencil Grasp Exercises on Handwriting in Sixth Grade Resource Students.

Hu, B., Rouse, E., \& Hargrove, L. (2018). Fusion of bilateral lower-limb neuromechanical signals improves prediction of locomotor activities. Frontiers Robotics AI, 5(JUN), 1-16. https://doi.org/10.3389/frobt.2018.00078

Ioannidi, V., \& Samara, E. (2019). Cognitive Difficulties in Writing . Early Educational Intervention. 6(2), 205-210.

Jiang, M. J., \& Rosengren, K. S. (2018). Action Errors: A Window Into the Early Development of Perception-Action System. Advances in Child Development and Behavior, 55(October), 145-171. https://doi.org/10.1016/bs.acdb.2018.04.002

John, S., \& Renumol, V. G. (2018). Impact of fine motor skill development app on handwriting performance in children with dysgraphia: A pilot study. ACM International Conference Proceeding Series, 11-16. https://doi.org/10.1145/3284497.3284502

Jones, B. D., Van Gemmert, A. W. A., \& Dalecki, M. (2021). Does Hand-Dominance Matter in NonStandard Visuomotor Transformations? Journal of Motor Behavior, 53(5), 622-631. https://doi.org/10.1080/00222895.2020.1817840

Kadaskar, V., \& Borkar, T. (2020). A Study to Evaluate the Correlation between Pinch Grip and Handwriting among School Going Children in Rural Areas. International Journal of Research, $7(2)$, 412-416. https://www.ijrrjournal.com/IJRR_Vol.7_Issue.2_Feb2020/IJRR0065.pdf

Kernc, D., Strojnik, V., \& Vengust, R. (2018). Early initiation of a strength training based rehabilitation after lumbar spine fusion improves core muscle strength: A randomized controlled trial. Journal of Orthopaedic Surgery and Research, 13(1), 1-8. https://doi.org/10.1186/s13018-018-0853-7

Kim, S., Coninx, A., \& Doncieux, S. (2021). From exploration to control: Learning object manipulation skills through novelty search and local adaptation. Robotics and Autonomous Systems, 136, 1-30. https://doi.org/10.1016/j.robot.2020.103710 
Lee, S. C. (2021). Visual Perceptual Skills as Predictors of Handwriting Skills of Children Grades 13. Journal of Occupational Therapy, Schools, and Early Intervention, 00(00), 1-9. https://doi.org/10.1080/19411243.2021.1959484

Liang, J., Wilkinson, K. M., \& Sainburg, R. L. (2019). Cognitive-perceptual load modulates hand selection in left-handers to a greater extent than in right-handers. Experimental Brain Research, 237(2), 389-399. https:// doi.org/10.1007/s00221-018-5423-z

Liang, J., Wilkinson, K., \& Sainburg, R. L. (2018). Is Hand Selection Modulated by Cognitiveperceptual Load? Neuroscience, 369(November), 363-373. https://doi.org/10.1016/j.neuroscience.2017.11.005

Lin, L. Y. (2019). Differences between preschool children using tablets and non-tablets in visual perception and fine motor skills. Hong Kong Journal of Occupational Therapy, 32(2), 118126. https://doi.org/10.1177/1569186119888698

Maulana, M. S. R. (2017). Peningkatan Motorik Halus Anak Usia Dini Di Era Revolusi Industri 4.0. Ekp, 13(3), 1576-1580. https://jurnalmahasiswa.unesa.ac.id/index.php/paudteratai/article/view/20065

Memon, H., Shimpi, A., Shyam, A., \& Sancheti, P. (2021). Can upper limb taping or exercises improve hand function, writing speed and self-perception of performance in adolescent school children? International Journal of Adolescent Medicine and Health, 33(1), 1-16. https://doi.org/10.1515/ijamh-2018-0065

Mohammed, M. A., \& Al-Noori, D. B. S. M. (2020). the Effect of Brainstorming As a Pre-Writing Strategy on Iraqi Efl Ma Learners' Writing Ability. International Journal of Research in Social Sciences and Humanities, 10(2). https:// doi.org/10.37648/ijrssh.v10i02.047

Naidoo, O., \& Moran, M. (2020). Promoting Early Literacy: A play Based Pre-writing Skills Program. https://www.ruralhealth.org.au/7rrhss/program/virtual-pre-symposiumpresenters?field_virtual_presenter_type_target_id=9

Natalia, R., \& Dwiana, A. (2019). Perbedaan tingkat intelegensia spasial antara pengguna dominan tangan kiri dengan pengguna dominan tangan kanan pada sekelompok mahasiswa di Universitas Tarumanagara. Tarumanagara Medical Journal, 2(1), 124-129.

Nurwulan, N. R., \& Kristiani, A. B. (2020). Potensi Kelainan Muskuloskeletal pada Siswa Kidal. $\begin{array}{llll}\text { Jurnal Kesehatan } \quad \text { Masyarakat Indonesia, } & \text { 15(2), }\end{array}$ https://doi.org/10.26714/jkmi.15.2.2020.9-12

Ortiz, C. M., \& Ortiz, C. M. (2020). Promoting Writing Development In Preschoolers Presented in Partial Fulfillment of the Department of Occupational Science and Occupational Therapy.

Puranik, C. S., Phillips, B. M., Lonigan, C. J., \& Gibson, E. (2018). Home literacy practices and preschool children's emergent writing skills: An initial investigation. Early Childhood Research Quarterly, 22(October 2017), 228-238. https://doi.org/10.1016/j.ecresq.2017.10.004

Queroda, P. G. (2018). Theme writing skills of Pangasinan State University (PSU) education students. TESOL International Journal, 13(3), 31-44.

Rahayu, N. I., Monica, A. D., Jajat, J., \& Sultoni, K. (2021). Hubungan physical activity dengan fine motor skills pada anak usia 4 tahun. Jurnal Keolahragaan, 9(1), 118-127. https://doi.org/10.21831/jk.v9i1.34156

Richmond, L., \& Marks, M. (2019). Effect of Ability to Cross Midline on Performance of Handwriting. Iso 690.

Rinaldi, L., Di Luca, S., Toneatto, C., \& Girelli, L. (2020). The effects of hemispheric dominance, literacy acquisition, and handedness on the development of visuospatial attention: A study in preschoolers and second graders. Journal of Experimental Child Psychology, 195, 104830. https://doi.org/10.1016/i.jecp.2020.104830

Runswick, O. R., Roca, A., Williams, A. M., Bezodis, N. E., \& North, J. S. (2018). The effects of anxiety and situation-specific context on perceptual-motor skill: a multi-level investigation. Psychological Research, 82(4), 708-719. https://doi.org/10.1007/s00426-017-0856-8

Scharoun Benson, S. M., Forsyth, A., \& Bryden, P. J. (2018). Hand selection in a preferential reaching task: The effects of object location, orientation, and task intention in preadolescent children. Brain and Behavior, 8(9), 1-7. https://doi.org/10.1002/brb3.1025 
Serpa-Andrade, L. J., Pazos-Arias, J. J., Lopez-Nores, M., \& Robles-Bykbaev, V. E. (2021). Design, Implementation and Evaluation of a Support System for Educators and Therapists to Rate the Acquisition of Pre-Writing Skills. IEEE Access, 9, 77920-77929. https://doi.org/10.1109/ACCESS.2021.3083496

Serrien, D. J., \& O'Regan, L. (2021). The development of motor planning strategies in children. European Journal of Developmental Psychology, 18(1), 1-17. https://doi.org/10.1080/17405629.2020.1736029

Sheedy, A. J., Brent, J., Dally, K., Ray, K., \& Lane, A. E. (2021). Handwriting Readiness among Digital Native Kindergarten Students. Physical and Occupational Therapy in Pediatrics, 41(6), 655-669. https://doi.org/10.1080/01942638.2021.1912247

Skar, G. B. U., Aasen, A. J., \& Jølle, L. (2020). Functional Writing in the Primary Years: Protocol for a Mixed-Methods Writing Intervention Study. Nordic Journal of Literacy Research, 6(1), 201. https:// doi.org/10.23865/njlr.v6.2040

Snyder, H. (2019). Literature review as a research methodology: An overview and guidelines. $\begin{array}{llll}\text { Journal of Business } & \text { Research, 104(July), }\end{array}$ https://doi.org/10.1016/j.jbusres.2019.07.039

Sumarni, S. S., Vianty, M., \& Andika, W. D. (2021). Readiness to Learn English for Early Childhood. Jurnal Obsesi: Jurnal Pendidikan Anak Usia Dini, 6(3), 1480-1492. https://doi.org/10.31004/obsesi.v6i3.1805

Sze, J., \& Southcott, J. (2020). Pencil or Keyboard? Boys' Preferences in Writing. The Qualitative Report, 25. https://doi.org/10.46743/2160-3715/2020.4621

Valentini, M., \& Lamanna, V. (2018). The importance of the body in writing. Journal of Physical Education and Sport, 18(2), 618-626.

Whittaker, S., Rose, N., \& Ward, T. (2019). Stylus For Fine-Motor Development. March. https://digital.wpi.edu/downloads/mg74qn45r

Yalçıntaş sezgin, E., Ulus, L., \& ŞAHIN, İ. (2019). The Examination of Relationship Between Behavioral Regulation with Phonological Awareness, Matching Images and Pre-Writing Skills in Preschool Children. Sakarya University Journal of Education, 107-128. https://doi.org/10.19126/suje.463610

Yeh, H. C., Heng, L., \& Tseng, S. S. (2020). Exploring the impact of video making on students' writing skills. Journal of Research on Technology in Education, 53(4), 446-456. https://doi.org/10.1080/15391523.2020.1795955

Yu, J. J., Burnett, A. F., \& Sit, C. H. (2018). Motor Skill Interventions in Children With Developmental Coordination Disorder: A Systematic Review and Meta-Analysis. In Archives of Physical Medicine and Rehabilitation (Vol. 99, Issue 10, pp. 2076-2099). Elsevier Inc. https://doi.org/10.1016/j.apmr.2017.12.009 